\title{
Knowledge of and attitude toward human papillomavirus infection and vaccines among female nurses at a tertiary hospital in Nigeria
}

This article was published in the following Dove Press journal:

International Journal of Women's Health

12 September 2011

Number of times this article has been viewed

\section{Christian Chigozie Makwe \\ Rose Ihuoma Anorlu \\ Department of Obstetrics and Gynaecology, College of Medicine, University of Lagos, Lagos, Nigeria}

\begin{abstract}
Background: Persistent infection with high-risk types of human papillomavirus (HPV) is a prerequisite for the development of cervical cancer. Highly immunogenic HPV vaccines have been developed and licensed for the primary prevention of cervical cancer in some developed and developing countries. This calls for assessment of the knowledge of the HPV infection and the acceptability of the HPV vaccines among health care providers.
\end{abstract}

Objective: The aim of this study was to assess awareness and knowledge of HPV infection and vaccines and to assess attitude toward these vaccines among female nurses at Lagos University Teaching Hospital, Lagos, Nigeria.

Study design: The study was a cross-sectional, descriptive study using a pretested, structured, anonymous, self-administered, 19-item questionnaire.

Results: A total of 178 female nurses were interviewed during a 4-week period. The mean age of respondents was $37.1 \pm 3.1$ years. Almost all (99.4\%) of the respondents had heard of cervical cancer, while about $85 \%$ of them had heard of HPV infection. Only a quarter $(25.3 \%)$ of respondents had heard of the HPV vaccines, and of those only $26.7 \%$ knew the vaccines were for the prevention of cervical cancer. Most (70.2\%) of the nurses expressed a desire to be vaccinated and 120 (67.4\%) supported the vaccination of preadolescent girls. Those who expressed a willingness to be vaccinated were more likely to recommend HPV vaccination for preadolescent girls.

Conclusion: Overall, there was a poor knowledge of the HPV vaccines among female nurses at Lagos University Teaching Hospital. Despite this poor knowledge, most of the nurses expressed a strong desire to be vaccinated and their intention to recommend it for preadolescent girls. The main reason given overall for not recommending the vaccines was lack of information. There is an urgent need to bridge this information gap.

Keywords: HPV, immunization, cervical cancer

\section{Introduction}

Human papillomavirus (HPV) is one of the most common sexually transmitted infections. ${ }^{1,2}$ Over $50 \%$ of sexually active women are exposed to at least one HPV type during their lifetime. ${ }^{2} \mathrm{HPV}$ infection occurs in women of all age groups and the highest rates of HPV infection are seen in women 20-24 years old. ${ }^{3}$ Most genital HPV infections are asymptomatic, transient, and resolve spontaneously without causing any disease. Genital HPV types have been classified as either high risk (mainly types 16 and 18) or low risk (mainly types 6 and 11), reflecting their potential risk of causing malignant lesions. Persistent infection of the cervix uteri with specific high-risk types of HPV is a prerequisite for the development of cervical intraepithelial neoplasia and cervical cancer. ${ }^{4} \mathrm{HPV}$ types 16 and 18 cause approximately $70 \%$ of cervical cancers.
Correspondence: Christian Chigozie Makwe Department of Obstetrics and Gynaecology, College of Medicine, University of Lagos/Lagos University Teaching Hospital, PMB I 2003, Idi-Araba, Lagos, Nigeria

Tel +234803335802।

Emailmakwe285@yahoo.com; ccmakwe@unilag.edu.ng 
Cancer of the cervix uteri is the second most common cancer in women and is the most common gynecologic malignancy worldwide. ${ }^{5}$ There were about 530,232 new cases in 2008 alone, and $85.5 \%$ of these occurred in developing countries. ${ }^{5}$ Cervical cancer is a major public health problem and it is the leading cause of cancer-related deaths among women in developing countries. ${ }^{6}$ It is hoped that the available HPV vaccines will markedly reduce the burden of cervical cancer and other HPV-related diseases in developing countries.

There are two types of HPV vaccine that have received regulatory approval for use in cervical cancer prevention programs worldwide. These vaccines are prepared with recombinant technology, using purified L1 structural proteins that self-assemble to form HPV type-specific empty shells or virus-like particles (VLPs). There is a bivalent HPV-16/18 VLP vaccine and a quadrivalent HPV-6/11/16/18 VLP vaccine. The vaccines are best administered prior to exposure to the virus, ideally during preadolescence (ie, 9-13 years of age) ${ }^{7}$

Several studies, mostly from developed countries, have shown that the knowledge of HPV infection and vaccines and the acceptability of these vaccines among health care providers and the general public vary from low to high. ${ }^{8-17}$ Nurses in developing countries play an important role in immunization programs, particularly those for vaccine-preventable childhood diseases. Nurses administer these vaccines and provide health education to the public. Therefore, the awareness and knowledge of HPV infection and the attitude toward HPV vaccines among nurses will greatly influence the success of an immunization program against cervical cancer. The aim of this study was to assess awareness and knowledge of HPV infection and vaccines and to assess attitude toward these vaccines among female nurses at Lagos University Teaching Hospital, Lagos, Nigeria.

\section{Materials and methods}

This prospective, cross-sectional, descriptive study was performed in the outpatient clinics, wards, theater, and the Accident and Emergency Unit of Lagos University Teaching Hospital, from January 21, 2008, to February 15, 2008. There were 415 female nurses in employment at the time of the study. The hospital is a 750-bed tertiary health care facility, which serves as a referral center for Lagos and its environs (Lagos has a population of about 15 million people).

The sample size was calculated using a formula for finite population. Assuming that $50 \%$ of the female nurses had sufficient knowledge of genital HPV infection, a minimum sample of 215 female nurses was calculated with $95 \%$ confidence and $5 \%$ reliability. The entire population of female nurses in the hospital was selected for the study. The questionnaire was delivered by hand during working hours and was collected after completion. The objectives of the study were explained to the nurses and their verbal consent was obtained before they were given a pretested, structured, anonymous, self-administered, 19-item questionnaire with both closed and open-ended questions. The questions sought information on sociodemographic characteristics, on awareness and knowledge of cervical cancer, HPV infections, and HPV vaccines, and on acceptance of these vaccines.

Data entry and analysis was performed using Epi Info ${ }^{\mathrm{TM}}$ (v 3.2.2; Centers for Disease Control and Prevention, Atlanta, GA) statistical software. Descriptive statistics were generated and data presented as a mean (standard deviation) or median (range) for continuous variables and as a percentage for categorical variables. Comparisons of categorical responses were evaluated using $\chi^{2}$-test or Fisher's exact test. A $P$-value of $<0.05$ was considered to be statistically significant. Ethical approval was obtained from the Health Research Ethics Committee of Lagos University Teaching Hospital.

\section{Results \\ Sociodemographic characteristics}

Two hundred and thirty questionnaires were distributed and 178 female nurses completed and returned their questionnaires. The response rate was $75.7 \%$ and the data were complete for all 178 respondents. Sociodemographic characteristics of the respondents are outlined in Table 1. The mean age was $37.1 \pm 3.1$ years. One hundred and sixteen $(65.2 \%)$ of the respondents were married, $56(31.5 \%)$ were single, three $(1.7 \%)$ were separated/divorced, and three $(1.7 \%)$ were widowed. One hundred and sixty-five $(92.7 \%)$ were Christians and 13 (7.3\%) were Muslims. Most (38.8\%) respondents were staff nurse midwives.

\section{Awareness and knowledge of HPV infection and vaccines}

One hundred and seventy-seven of the nurses (99.4\%) had heard of cervical cancer and $151(84.8 \%)$ had heard of HPV infection (see Table 2). The majority (70.1\%) of them were aware of the association between cervical cancer and HPV infection. Most (72.9\%) of the nurses who had heard of cervical cancer knew it could be prevented by Pap smear, while only $13 \%$ of them knew it could be prevented through vaccination.

About $90 \%$ of the nurses who had heard of HPV infection knew that it could be transmitted through sexual intercourse, 
Table I Sociodemographic characteristics $(n=178)$

\begin{tabular}{lll}
\hline Age distribution (years) & Respondents (n) & Respondents (\%) \\
\hline $20-29$ & 56 & 31.4 \\
$30-39$ & 50 & 28.1 \\
$40-49$ & 50 & 28.1 \\
$\geq 50$ & 22 & 12.4 \\
Marital status & & \\
Single & 56 & 31.5 \\
Married & 116 & 65.2 \\
Divorced/separated & 3 & 1.7 \\
Widowed & 3 & 1.7 \\
Religion & & \\
Christian & 165 & 92.7 \\
Muslim & 13 & 7.3 \\
Tribe & & \\
Yoruba & 96 & 53.9 \\
lbo & 42 & 23.6 \\
Other & 40 & 22.5 \\
Position/Designation & & \\
CNO & 25 & 14.0 \\
Assistant CNO & 15 & 8.4 \\
Principal NO & 33 & 18.5 \\
Senior NO & 14 & 7.9 \\
NO & 22 & 12.4 \\
Staff nurse midwife & 69 & 38.8 \\
\hline Abbreviations: CNO & &
\end{tabular}

Abbreviations: CNO, chief nursing officer; NO, nursing officer; n, number.

while only eleven (7.3\%) knew it could be transmitted by skin-to-skin contact. Less than half of the respondents who had heard of genital HPV infection knew that it could be prevented by vaccination (31.8\%) and condom use (33.1\%).

Most (74.7\%) of the respondents had never heard of the HPV vaccines. Among the 45 nurses who had heard of the vaccines, only twelve (26.7\%) knew they were for the prevention of cervical cancer, while $30(66.7 \%)$ respondents thought they were for the prevention of HPV infection.

\section{HPV vaccine acceptability}

As Table 2 shows, 125 (70.2\%) of the nurses stated they would want to be vaccinated, while 53 (29.8\%) were unwilling to be vaccinated; the main reason given for unwillingness was insufficient knowledge about the HPV vaccines.

The majority (67.4\%) of respondents supported vaccination of preadolescent girls, while 58 (32.6\%) did not. The reasons given for not recommending HPV vaccination for preadolescent girls included (1) they are too young; (2) they are not yet sexually active; (3) they are not at risk for HPV infection; (4) vaccination will encourage premarital sex; and (5) the respondent had insufficient knowledge about the vaccines and its complications. Almost all the participants (99.4\%) expressed a desire to have more information on HPV vaccines.
Table 2 Awareness and knowledge of cervical cancer, human papillomavirus (HPV) infection, and HPV vaccines, and acceptability of these vaccines $(n=178)$

\begin{tabular}{|c|c|c|}
\hline Question & Yes (n) & Yes (\%) \\
\hline Ever heard of cervical cancer? & 177 & 99.4 \\
\hline Ever heard of HPV infection? & $|5|$ & 84.8 \\
\hline Ever heard of HPV vaccine? & 45 & 25.3 \\
\hline $\begin{array}{l}\text { Would you want to receive a vaccine } \\
\text { that can prevent cervical cancer? }\end{array}$ & 125 & 70.2 \\
\hline $\begin{array}{l}\text { Would you support vaccination } \\
\text { of preadolescent girls? }\end{array}$ & & 67.4 \\
\hline \multirow[t]{2}{*}{ Knowledge of cervical cancer ${ }^{a}$} & \multicolumn{2}{|c|}{ Correct response } \\
\hline & (n) & $(\%)$ \\
\hline $\begin{array}{l}\text { Cervical cancer is the commonest } \\
\text { gynecological cancer in Nigeria }\end{array}$ & $17 \mid$ & 96.6 \\
\hline \multicolumn{3}{|l|}{ HPV infection } \\
\hline Cervical cancer is preventable & 164 & 92.7 \\
\hline \multicolumn{3}{|l|}{$\begin{array}{l}\text { How can cervical cancer be } \\
\text { prevented? }\end{array}$} \\
\hline Pap smear & 129 & 72.9 \\
\hline Vaccination & 23 & 13.0 \\
\hline \multicolumn{3}{|l|}{ Knowledge of HPV infection ${ }^{b}$} \\
\hline $\begin{array}{l}\text { HPV infection is associated with } \\
\text { genital warts }\end{array}$ & genital warts & 77.5 \\
\hline \multicolumn{3}{|l|}{ How is HPV infection transmitted? } \\
\hline Sexual contact & 135 & 89.4 \\
\hline Skin-to-skin contact & 11 & 7.3 \\
\hline \multicolumn{3}{|l|}{$\begin{array}{l}\text { How can genital HPV infection be } \\
\text { prevented? }\end{array}$} \\
\hline Sexual abstinence & 63 & 41.7 \\
\hline Condom use & 50 & 33.1 \\
\hline Vaccination & 48 & 31.8 \\
\hline \multicolumn{3}{|l|}{ Knowledge of HPV vaccine ${ }^{c}$} \\
\hline \multicolumn{3}{|l|}{ What is the HPV vaccine used for? } \\
\hline Prevention of HPV infection & 30 & 66.7 \\
\hline Prevention of cervical cancer & 12 & 26.7 \\
\hline Prevention of genital warts & 5 & II.I \\
\hline \multicolumn{3}{|l|}{ Age group eligible for the } \\
\hline \multicolumn{3}{|l|}{ HPV vaccine } \\
\hline $9-26$ years & 11 & 24.4 \\
\hline
\end{tabular}

Notes: aOnly respondents who had heard of cervical cancer; 'only respondents who had heard of HPV infection; 'only respondents who had heard of HPV vaccine. Abbreviation: n, number.

The awareness of HPV infection, cervical cancer, and the vaccines had no significant association with the willingness to be vaccinated or the intention to recommend the vaccine for preadolescent girls. The nurses who were willing to be vaccinated were more likely to recommend the vaccines for preadolescent girls $(P<0.001)$ (Table 3$)$.

\section{Discussion}

The knowledge of HPV infection and vaccines among nurses in this study was relatively low. Despite the fact that many were aware of cervical cancer and HPV infection, a relatively 
Table 3 Relationship between awareness of human papillomavirus (HPV) infection, cervical cancer, and HPV vaccines and acceptance of these vaccines

\begin{tabular}{|c|c|c|c|c|}
\hline \multirow[t]{2}{*}{ Awareness } & \multicolumn{4}{|c|}{ Willingness to receive HPV vaccine } \\
\hline & Yes $(n=125)$ & No $(n=53)$ & $\chi^{2}$-Test & $P$-value \\
\hline \multicolumn{5}{|c|}{ Ever heard of HPV infection? } \\
\hline Yes & 104 & 47 & 0.87 & 0.351 \\
\hline No & 21 & 6 & & \\
\hline \multicolumn{5}{|c|}{ Ever heard of cervical cancer? } \\
\hline Yes & 124 & 53 & NA & $1.000 *$ \\
\hline No & 1 & 0 & & \\
\hline \multicolumn{5}{|c|}{ Ever heard of HPV vaccine? } \\
\hline Yes & 32 & 13 & 0.02 & 0.880 \\
\hline \multirow[t]{3}{*}{ No } & 93 & 40 & & \\
\hline & \multicolumn{4}{|c|}{ Intention to recommend HPV vaccine to preadolescent girls } \\
\hline & Yes $(n=120)$ & No $(n=58)$ & $\chi^{2}$-Test & $P$-value \\
\hline \multicolumn{5}{|c|}{ Ever heard of HPV infection? } \\
\hline Yes & 104 & 47 & 0.96 & 0.326 \\
\hline No & 16 & 11 & & \\
\hline \multicolumn{5}{|c|}{ Ever heard of cervical cancer? } \\
\hline Yes & 119 & 58 & NA & $1.000 *$ \\
\hline No & 1 & 0 & & \\
\hline \multicolumn{5}{|c|}{ Ever heard of HPV vaccine? } \\
\hline Yes & 31 & 14 & 0.06 & 0.807 \\
\hline No & 89 & 44 & & \\
\hline \multicolumn{5}{|c|}{ Willing to receive vaccine? } \\
\hline Yes & 97 & 28 & 19.82 & $<0.001$ \\
\hline No & 23 & 30 & & \\
\hline
\end{tabular}

Note: *Fisher's exact test.

Abbreviations: NA, not available; n, number.

low proportion (70.1\%) knew about the association between HPV infection and cervical cancer. In similar studies in Greece, New Zealand and Thailand the proportions of nurses who knew about this association were $78.5 \%, 71 \%$, and $81.8 \%$ respectively. ${ }^{18-20}$

Several studies have shown that knowledge of HPV infection is high in countries with existing national HPV education programs. These programs have led to an improved awareness and knowledge of HPV infection and related diseases among health care providers and the general public.

In this Nigerian study, only a quarter of the nurses who had heard about the vaccines knew they were for the prevention of cervical cancer. This is relatively low compared with $39.1 \%$ in the Thailand. ${ }^{20}$ The poor knowledge of the HPV vaccines among the nurses in this Nigerian study may be due to the lack of HPV and cervical cancer education programs in Nigeria. The vaccines were launched in Nigeria in September 2008, long after the study was conducted.

Over two-thirds of the female nurses were willing to be vaccinated. This is a similar result to that obtained from nurses in the Thai study. ${ }^{20}$ Most (67.4\%) of the nurses were also willing to recommend the HPV vaccines for preadolescent girls.
This finding is consistent with what has been reported in other recent studies. ${ }^{9,10,15,17,21}$ These studies found there was a high level of public interest in HPV vaccination, despite an overall low knowledge about HPV infection and related diseases. Studies have also shown that the main predictors of providers' intention to recommend HPV vaccination are endorsement by professional organizations and provider knowledge of and attitude toward HPV vaccination. ${ }^{19,21,22}$ Likewise, the authors found that the nurses who were willing to be vaccinated were more likely to recommend the vaccine for preadolescent girls.

The main reason given by many of the nurses for not accepting the HPV vaccines or recommending them for preadolescent girls was insufficient information about the efficacy and safety of the vaccines. Another reason given was that preadolescent girls were not at risk for HPV infection or cervical cancer and therefore had no need for the vaccines. Other studies have also identified these factors as barriers to effective HPV immunization. ${ }^{10,23-25}$ Almost all of the nurses expressed their desire to receive more information about the vaccines.

The potential limitations of this study include the relatively small sample size and the fact that, as a self-administered 
questionnaire was used to collect data, it is possible that some respondents might have given incorrect information.

\section{Conclusion}

The knowledge of the HPV infection and vaccines among female nurses in this study was poor. Despite their poor knowledge, most of the nurses were willing to be vaccinated and would recommend the vaccines for preadolescent girls. The main reason given overall for not recommending the vaccines was lack of information. There is an urgent need to bridge this information gap through a well-designed HPV education program integrated into a national cervical cancer prevention and control program.

\section{Acknowledgments}

Special thanks to the nursing staff and the Department of Nursing Services of Lagos University Teaching Hospital, Dr Ezekiel S Oridota of the Department of Community Health and Primary Health Care, College of Medicine, University of Lagos, and Mrs Florence Chizobam Okoro.

\section{Disclosure}

The authors report no conflicts of interest in this work.

\section{References}

1. Cates W Jr. Estimates of the incidence and prevalence of sexually transmitted diseases in the United States: American Social Health Association Panel. Sex Transm Dis. 1999;26(4 Suppl):S2-S7.

2. Baseman JG, Koutsky LA. The epidemiology of human papillomavirus infections. J Clin Virol. 2005;32 Suppl 1:S16-S24.

3. Dunne EF, Unger ER, Sternberg M. Prevalence of HPV infection among females in the United States. JAMA. 2007;297(8):813-819.

4. Moscicki A, Schiffmanb M, Kjaer S, Villa LL. Updating the natural history of HPV and anogenital cancer. Vaccine. 2006;24 Suppl 3: S42-S51.

5. Ferlay J, Shin HR, Bray F, Forman D, Mathers C, Parkin DM. Estimates of worldwide burden of cancer in 2008: GLOBOCAN 2008. Int J Cancer. 2010;127(12):2893-2917.

6. Anorlu RI. Cervical cancer: the sub-Saharan African perspective. Reprod Health Matters. 2008;16(32):41-49.

7. World Health Organization. WHO position on HPV vaccines. Vaccine. 2009;27(52):7236-7237.

8. Jain N, Euler GL, Shefer A, Lu P, Yankey D, Markowitz L. Human papillomavirus (HPV) awareness and vaccination initiation among women in the United States, National Immunization Survey-Adult 2007. Prev Med. 2009;48(5):426-431.
9. Dursun P, Altuntas B, Kuscu E, Ayhan A. Women's knowledge about human papillomavirus and their acceptance of HPV vaccine. Aust NZ J Obstet Gynaecol. 2009;49(2):202-206.

10. Christian WJ, Christian A, Hopenhayn C. Acceptance of the HPV vaccine for adolescent girls: analysis of state-added questions from the BRFSS. J Adolesc Health. 2009;44(5):437-445.

11. Klug SJ, Hukelmann M, Blettner M. Knowledge about infection with human papillomavirus: a systematic review. Prev Med. 2008;46(2): $87-98$

12. Riedesel JM, Rosenthal SL, Zimet GD, et al. Attitudes about human papillomavirus vaccine among family physicians. $J$ Pediatr Adolesc Gynecol. 2005;18(6):391-398.

13. Daley MF, Liddon N, Crane LA, et al. A national survey of pediatrician knowledge and attitudes regarding human papillomavirus vaccination. Pediatrics. 2006;118(6):2280-2289.

14. Songthap A, Pitisuttithum P, Kaewkungwal J, Fungladda W, Bussaratid V, Koonsaeng S. Knowledge, attitudes, and acceptability of a human papillomavirus vaccine among healthcare providers. Southeast Asian J Trop Med Public Health. 2009;40(5):1048-1056.

15. Kwan TT, Chan KK, Yip AM, et al. Acceptability of human papillomavirus vaccination among Chinese women: concerns and implications. BJOG. 2009;116(4):501-510.

16. Jones $\mathrm{M}$, Cook $\mathrm{R}$. Intent to receive an HPV vaccine among university men and women and implications for vaccine administration. $\mathrm{J} \mathrm{Am} \mathrm{Coll}$ Health. 2008;57(1):23-32.

17. Tozzi AE, Rava L, Stat D, Pandolfi E, Marino MG, Ugazio AG. Attitudes towards HPV immunization of Italian mothers of adolescent girls and potential role of health professionals in the immunization program. Vaccine. 2009;27(19):2625-2629.

18. Dinas K, Nasioutziki M, Arvanitidou O, et al. Awareness of human papillomavirus infection, testing and vaccination in midwives and midwifery students in Greece. J Obstet Gynaecol. 2009;29(6):542-546.

19. Henninger J. Human papillomavirus and papillomavirus vaccines: knowledge, attitudes and intentions of general practitioners and practice nurses in Christchurch. J Prim Health Care. 2009;1(4):278-285.

20. Nganwai P, Truadpon P, Inpa C, et al. Knowledge, attitudes and practices vis-a-vis cervical cancer among registered nurses at the Faculty of Medicine, Khon Kaen University, Thailand. Asian Pac J Cancer Prev. 2008;9(1):15-18.

21. Kahn JA, Ding L, Huang B, Zimet GD, Rosenthal SL, Frazier AL. Mothers' intention for their daughters and themselves to receive the human papillomavirus vaccine: a national study of nurses. Pediatrics. 2009;123(6):1439-1445.

22. Kahn JA, Rosenthal SL, Hamann T, Bernstein DI. Attitudes about human papillomavirus vaccine in young women. Int J STD AIDS. 2003; 14(5):300-306.

23. Li J, Li LK, Ma JF, et al. Knowledge and attitudes about human papillomavirus (HPV) and HPV vaccines among women living in metropolitan and rural regions of China. Vaccine. 2009;27(8):1210-1215.

24. Black LL, Zimet GD, Short MB, Sturm L, Rosenthal SL. Literature review of human papillomavirus vaccine acceptability among women over 26 years. Vaccine. 2009;27(11):1668-1673.

25. Reiter PL, Brewer NT, Gottlieb SL, McRee AL, Smith JS. Parents' health beliefs and HPV vaccination of their adolescent daughters. Soc Sci Med. 2009;69(3):475-480.
International Journal of Women's Health

\section{Publish your work in this journal}

The International Journal of Women's Health is an international, peerreviewed open-access journal publishing original research, reports, reviews and commentaries on all aspects of women's healthcare including gynecology, obstetrics, and breast cancer. Subject areas include: Chronic conditions (migraine headaches, arthritis, osteoporosis);

\section{Dovepress}

Endocrine and autoimmune syndromes; Sexual and reproductive health; Psychological and psychosocial conditions. The manuscript management system is completely online and includes a very quick and fair peer-review system. Visit http://www.dovepress.com/ testimonials.php to read real quotes from published authors. 